\title{
Stochastic Rates of Return for Social Security under Various Policy Scenarios
}

\author{
Michael Anderson \\ Mountain View Research \\ Hisashi Yamagata \\ Department of Demography, UC Berkeley \\ Shripad Tuljapurkar \\ Mountain View Research \\ Ronald Lee \\ Department of Demography and Department of Economics, UC Berkeley
}

Prepared for the Third Annual Conference of the Retirement Research Consortium "Making Hard Choices About Retirement"

May 17-18, 2001

Washington, DC.

The research reported herein was performed pursuant to a grant from the U.S. Social Security Administration (SSA) to the Michigan Retirement Research Center (MRRC). The opinions and conclusions are solely those of the authors and should not be construed as representing the opinions or policy of SSA or any agency of the Federal Government or of either the CRR or MRRC. Some closely related research was also supported by the Center for the Economics and Demography of Aging at U.C. Berkeley, which is supported by the National Institutes of Health. 


\section{Introduction}

One tool for providing insight into the consequences of a pension system on its participants is to estimate an individual's "rate of return" (ROR) on their contributions in terms of the benefits they subsequently receive. That is, if the participant had invested their contributions at some ROR, what rate $r$ would result in the amount of benefits actually received? Equivalently, what discount rate makes the total present value of contributions equal to the total present value of benefits? This rate $r$ is defined as the internal ROR.

This measure gives us a means of analyzing the impact of any pension reform on each generation of cohorts. This is particularly informative since many proposed policies of reform would have vastly different effects across cohorts. For example, a strategy of simply allowing the Trust Fund to persist on its present course, simply cutting benefits once the fund goes bankrupt, would place the cost of reform entirely on the shoulders of cohorts born lately enough to suffer this benefit cut. An immediate benefit cut, on the other hand, would shift some of the burden to older cohorts.

This paper calculates ROR's for the OASI trust fund for three different scenarios. First, we estimate ROR's for the presently legislated tax and benefit schedules, under which the fund is forecasted to face insolvency in 2038. Since this is an unrealistic outcome, for which the interpretation of an ROR is somewhat ambiguous, we also estimate ROR's for two alternative policy scenarios in which the fund is projected to remain solvent for a 75-year horizon. First, we immediately increase the overall OASDI tax rate by $2 \%$, which results in a $49 \%$ chance of solvency through 2074 . Second, we

return the tax rate to the legislated level, and instead raise the Normal Retirement Age to age 69 by 2024, under which there is a 46\% chance of solvency through 2074.

\section{Literature}

Internal ROR's (also known as “money's worth measures”) for the Social Security system have been analyzed by a number of researchers. Unfortunately the analyses are often quite disparate, analyzing either different cohorts or different components of the Social Security system. Leimer (1995) presents a good overall summary of the issues and complications faced by these researchers. Geanakoplos, 
Mitchell and Zeldes (1998) also provide an extensive discussion of ROR estimation under various policy scenarios, and more recently Bosworth, Burtless and Steuerle (1999) present a general analysis of career earnings patters as they may affect Social Security reform.

Efforts at estimating ROR's for Social Security date back at least 25 years. Freiden, Leimer and Hoffer (1976) analyzed OAI benefits for workers only (excluding survivors', disability and so on) for workers retiring between 1967 and 1970. For these older cohorts, ROR's were estimated at roughly $25 \%$, a rather high return due to the payas-you-go structure of the system, which required relatively small amounts of taxes from these beneficiaries. Boskin, Kotlikoff, et al. (1987) calculated expected rates of return for the retirement portion of Social Security for cohorts born in 1915, 1930, 1945, 1960, 1975 and 1990. Their results depend highly on earnings level and family type, but for the 1945 cohort they range from $3.5 \%$ for poorer 1-earner couples to $-0.79 \%$ for richer single males. Boskin and Puffert (1987) analyzed OASI cohorts from before 1912 to 1992 for the presently legislated scenario, and found ROR's ranging from $11.61 \%$ for the older cohorts to $2.3 \%$ for the youngest cohorts. They also computed ROR's for various economic and demographic scenarios as assumed by the Social Security Administration. Duggan, Gillingham and Greenless (1993) analyzed OASI beneficiaries born from 1895 to 1922 and found ROR's ranging from of $12.5 \%$ for the oldest cohorts to $5.9 \%$ for the youngest.

A more extensive analysis of OASI was completed by Leimer (1994), which estimated ROR's for single-year cohorts born from 1876 to 2050 for three scenarios: The presently legislated program (under which the fund likely faces insolvency), an balancedbudget through increased taxes scenario, and a balanced-budget through benefits reduction scenario. Under the presently legislated numbers, Leimer finds ROR's ranging from $11.1 \%$ for the oldest cohorts, falling to $3 \%$ by the 1938 cohort, and falling to $1.7 \%$ through 2050. Of course, tax increases and benefits reduction further reduce these ROR's for surviving cohorts. Under the tax increase scenario, the ROR decreases to $0.94 \%$ for the 2050 cohort, and under the benefits reduction scenario, it falls to $0.8 \%$. 


\section{Theory and methods}

In this paper we define the real, internal ROR as that rate $r$ which satisfies the equation:

$$
0=\mathbf{E}_{\mathrm{x}}[\mathrm{B}(\mathrm{x})-\mathrm{T}(\mathrm{x})] \mathrm{e}^{-\mathrm{rx}} \mathrm{L}_{\mathrm{x}}
$$

[Equation 1]

where $\mathrm{x}$ is the age of the participant, $\mathrm{B}(\mathrm{x})$ is the average per-capita OASI benefit earned at age $x, T(x)$ is the average per-capita OASI tax paid at age $x$, and $L_{x}$ is the number of cohort person years lived at age $\mathrm{x}$. The sum is calculated from age 0 to age 100 .

The literature discusses a number of problematic decisions in the formation of ROR estimates in this manner. First, there is the problem of how to allocate the employer's portion of the payroll tax. In accordance with most past research, we assume that this cost is actually born by the employee. Secondly, there is the issue of how to deal with benefits received by persons other than the original taxpayer (i.e. survivors' benefits). We do not reallocate benefits received by adult survivors, but we do redistribute benefits received by children (18 and under) to their parents according to the average level of fertility by age, plus the age of the beneficiary. We also reallocate the taxes paid by children in an additional manner, although this amount is small.

More substantially, there is the problem of how to estimate taxes and benefits for participants who are still alive. As this paper includes those born from 1941 to 1999, this includes all the cohorts analyzed. For example, the cohort born in 1941 is just about to retire, so most taxes paid by this cohort are historical, while most benefits are forecasted. For the youngest cohort, all taxes and benefits must be forecasted.

We use a combination of historical data and stochastic forecasts of productivity growth rates and mortality rates to estimate full lifetime trajectories of tax and benefit payments for all cohorts born between 1941 and 1999. The result is that the ROR estimates themselves are stochastic; that is, we compute a distribution of ROR's for each cohort. The interpretation is that the distribution of a ROR for a given cohort reflects the uncertainty about their future tax and benefits. Thus, for the oldest cohorts the uncertainty is relatively smaller, since all of their tax payment history and much of their benefits and mortality history is known, whereas the youngest cohorts face much greater 
uncertainty since most of their taxes and benefits will be paid well into the future.

The historical data come from two sources. Age- and sex-specific Tax profiles for 1941 to 1999 were estimated from the Continuous Work History Sample, a 1\% sample of participants, provided by the Social Security Administration. Age-and sexspecific benefits data for 1941 to 1999 were taken the Annual Statistical Supplements to the Social Security Bulletin. See Leimer (1994) for a more detailed discussion of these estimates. We computed per-capita profiles were formed by dividing the age- and sexspecific tax and benefit totals by the SSA's Area Population counts. These estimates were then converted to 1999 dollars using the Consumer Price Index as taken from the 1999 Trustees' Report.

The computation of stochastic tax and benefit profiles was substantially more complicated. For this purpose, we used the stochastic forecasting simulation described by Anderson, Tuljapurkar and Lee (1999). This model starts with the known Trust Fund balances as of the end of calendar year 1999, and simulates the trust fund with randomly generated trajectories. Briefly, this model uses an autoregressive model of productivity growth, combined with stylized demographic forecasts (see Lee and Tuljapurkar, 1994). Mortality was forecasted with a single-year form of the Lee-Carter model for mortality (Lee and Carter, 1992) using the SSA's historical lifetables.

For tax and benefits, we started with the known sex- and age-specific OASDI tax and benefit profiles for 1999, and updated these according to the stochastic forecasts of productivity growth. Other variables were also used to adjust taxes and benefits according to likely shifts in the composition of workers, the Normal Retirement Age, and disability recipients. Tax profiles were updated annually using projections of the age-sex profiles of labor force participation based on SSA actuarial reports and our own analyses, both of which agree.

Benefit profiles were complicated by the difference between OASI and DI benefits. Initial per-capita age-sex-specific benefit profiles are estimated using SSA's Table 5.A1 in the Annual Statistical Supplement. These were decomposed into OASI and DI profiles. The DI profiles were adjusted on the assumption that the age-pattern of benefits will stay the same over time, though applied to a changing age structure. The level of DI benefits changes with the growth rate of productivity, and also scales up to 
reflect the SSA's long-term assumptions about changes in the prevalence of DI beneficiaries in the population. In practice, we estimate the prevalence change using a calibration of our program outputs, when we incorporate SSA median assumptions, against the SSA median projection.

OASI benefits are treated differently. We update the age-profiles of OASI benefits using (i) a time-lagged productivity factor for each cohort that takes into account the productivity adjustment of average wages through the age at which the maximum benefit calculation is done; (ii) an age-specific hazard rate that specifies what fraction of each cohort will elect to take benefits at different ages from 62 to 70 . This hazard rate has an age-profile as estimated by SSA actuaries (and other studies), with peaks in benefit election at the earliest eligible age and the NRA; (iii) a tax rate applied to benefits that is based on current law.

The full OASDI tax and benefit profiles were used in the simulation program in order to determine what policy reforms were necessary in order to result in a near-50\% chance of solvency for the entire OASDI program. The profiles were subsequently decomposed into OASI and DI profiles, after which only the OASI profiles were used for the purposes of this paper. The sex-specific profiles were then recombined into sexescombined profiles according to the sex-specific stochastic population distributions in the forecasts used by the simulation.

Once the estimation of tax and benefit profiles was completed, sexes-combined ROR estimates were formulated for all cohorts from 1941 to 1999 in conjunction with the stochastic forecasts of persons-years lived as derived from the mortality forecasts used in the overall OASDI Trust Fund simulation. A total of 200 trajectories was used, and the Matlab function $f \min ($ ) was used to solve for Equation1 for all cohorts and trajectories.

\section{Results}

First the ROR was calculated by cohort for the legislated, baseline scenario. Table 1 shows the results for cohorts born in 1941, 1949, 1959, 1969, 1979, 1989 and 1999. The median estimate of $2.77 \%$ for the 1941 cohort is quite close to Leimer's (1994) estimate of $2.62 \%$, but interestingly this latter estimate also lies outside of the lower bound of the $95 \%$ confidence interval for our stochastic estimates. 
The median rate of return initially decreases by cohort, but then increases again for the younger cohorts, in contrast to Leimer's estimates, which generally fall to about $1.7 \%$ with the decreasing age of the cohorts. This is likely due largely to the substantially higher forecasts of life expectancy used in our model.

The variance in the estimates is quite small for the 1941 cohort, for which the $95 \%$ prediction interval is less than $0.3 \%$ in width. As expected however, the range increases substantially for the younger cohorts, with a $95 \%$ prediction interval of about $0.85 \%$ in width. This is due to the increased uncertainty in having to forecast an increased proportion of taxes and benefits further into the future.

Table 1. Percentage rate of return by cohort for legislated scenario

\begin{tabular}{l|l|l|l|l|l|} 
cohort & 2.5 percentile & 16.7 percentile. & median & 83.3 percentile & 97.5 percentile \\
\hline 1941 & 2.6372 & 2.6977 & 2.7708 & 2.8335 & 2.9118 \\
\hline 1949 & 2.0747 & 2.2107 & 2.3415 & 2.4763 & 2.6094 \\
\hline 1959 & 2.0822 & 2.2259 & 2.3954 & 2.5751 & 2.7741 \\
\hline 1969 & 2.2924 & 2.4499 & 2.6145 & 2.8087 & 2.9930 \\
\hline 1979 & 2.1704 & 2.3816 & 2.5395 & 2.7374 & 2.9387 \\
\hline 1989 & 2.2060 & 2.3849 & 2.5919 & 2.7761 & 3.0319 \\
\hline 1999 & 2.2346 & 2.3836 & 2.6154 & 2.7984 & 3.0830
\end{tabular}

Figure 1 plots the above percentiles, in addition to three randomly chosen stochastic trajectories by cohort to illustrate the degree of inter-cohort variance from year to year. Figure 2 shows the distribution of rates of return for the cohorts born in 1941, 1970, and 1999. The distributions are roughly normal in shape, and increase in variance substantially as the age of the cohort decreases.

Next we calculated rates of return for a balanced-budget scenario, in which the overall OASDI payroll tax rate was increased from $12.4 \%$ to $14.4 \%$. (This amounts to a $1.77 \%$ increase in the OASI tax rate). Under this scenario, the OASDI Trust Fund has a $49 \%$ chance of remaining solvent through 2074 , according to estimates generated by our stochastic simulation model (see Anderson, Tuljapurkar and Lee, 1999). 
Table 2 presents the percentiles of the rates of return for the tax increase scenario, and Figure 3 plots these percentiles along with three randomly chosen trajectories of ROR's by cohort. As expected, the oldest cohorts remain largely unaffected by a tax increase since their taxpaying days have mostly passed, while the ROR decreases substantially for cohorts born after 1950. The median rate for the 1999 cohort falls to $2.194 \%$, compared with the (unrealistic) rate of $2.615 \%$ for the presently legislated scenario.

Table 2. Percentage rate of return by cohort for $2 \%$ tax increase scenario

\begin{tabular}{l|l|l|l|l|l|} 
cohort & 2.5 percentile & 16.7 percentile & median & 83.3 percentile & 97.5 percentile \\
\hline 1941 & 2.5851 & 2.6463 & 2.7205 & 2.7841 & 2.8628 \\
\hline 1949 & 1.9427 & 2.0832 & 2.2149 & 2.3535 & 2.4856 \\
\hline 1959 & 1.8324 & 1.9788 & 2.1515 & 2.3303 & 2.5421 \\
\hline 1969 & 1.9316 & 2.0883 & 2.2615 & 2.4562 & 2.6458 \\
\hline 1979 & 1.7343 & 1.9528 & 2.1063 & 2.3085 & 2.5052 \\
\hline 1989 & 1.7711 & 1.9510 & 2.1670 & 2.3457 & 2.6038 \\
\hline 1999 & 1.8104 & 1.9599 & 2.1940 & 2.3764 & 2.6623
\end{tabular}

Figure 4 shows the distribution of ROR's for the 1941, 1970 and 1999 cohorts. Again, the distributions shift substantially to the left, but the uncertainty in estimates remains comparable to the uncertainty in estimates calculated under the legislated scenario.

Finally, we implemented an increase in the Normal Retirement Age. Presently the NRA is scheduled to increase to age 66 within the next six years, and again to age 67 starting in 2017. In our stochastic simulation of the OASDI Trust Fund, we increased the NRA to age 69 by 2024, which results in a 46\% chance of solvency through 2074. Disability Insurance was allowed to continue for the extra years of OASI non-eligibility, but we do not assume that any increase in taxes would occur as a result of extended employment.

Table 3 shows the percentiles of the ROR estimates, and Figure 5 plots these 
estimates along with three randomly chosen trajectories by cohort. As expected, this shift in the NRA causes the bulk of the reform to fall on the backs of cohorts born after the early 1960's while older cohorts are largely unaffected. Indeed, the ROR of return for cohorts born after 1963 fall by more than a percentage point compared with the presently legislated scenario. This is the result of a "double-whammy" effect, in which not only is the reform directed entirely to younger cohorts, but the extended delay in the implementation of reform (compared with the immediately implemented tax increase for example) necessitates a much more substantial effort to shore up the fund. This is because an immediate tax increase allows interest to be accumulated over the next twenty years, substantially alleviating the need for reform in the long run.

Table 3. Percentage rate of return by cohort for NRA increase to 69

\begin{tabular}{l|l|l|l|l|l|} 
cohort & 2.5 percentile & 16.7 percentile & median & 83.3 percentile & 97.5 percentile \\
\hline 1941 & 2.6372 & 2.6977 & 2.7708 & 2.8335 & 2.9118 \\
\hline 1949 & 1.9369 & 2.0775 & 2.2058 & 2.3476 & 2.4798 \\
\hline 1959 & 1.7818 & 1.9292 & 2.1044 & 2.2883 & 2.4943 \\
\hline 1969 & 1.0978 & 1.2760 & 1.4726 & 1.6970 & 1.9033 \\
\hline 1979 & 0.9768 & 1.2173 & 1.4102 & 1.6475 & 1.8884 \\
\hline 1989 & 1.0206 & 1.2239 & 1.4868 & 1.7077 & 2.0064 \\
\hline 1999 & 1.0759 & 1.2702 & 1.5374 & 1.7808 & 2.1126
\end{tabular}

Figure 6 shows the distribution of ROR's for the cohorts born in 1941, 1970 and 1999. It appears that not only does the NRA shift decrease ROR's in general for younger cohorts, it also increases the uncertainty in these estimates somewhat. This effect is more evident in Figure 7, which plots the variance in the ROR estimates by cohort for the three scenarios above. In all three cases, the variance increases substantially over time, as expected. However, while the within-cohort variance is quite comparable for the legislated and tax increase scenarios, the increased NRA scenario results in substantially greater uncertainty for cohorts born after the early 1960's. 


\section{Conclusions}

There are some difference between our estimates of the ROR estimates presented previously (e.g. Leimer, 1994). Our estimates are somewhat higher than Leimer's, particularly for younger cohorts. One reason is that our mortality rate forecasts are substantially lower than previous SSA forecasts, particularly at retirement ages. Secondly, in Equation 1 for the ROR calculation, we include the survival probabilities (person-years lived) for the present valuation of taxes as well as benefits; Leimer weights only benefits by survival probabilities.

The estimation of ROR's under the three policy scenarios illustrates some interesting patterns in the rates of return and the uncertainty in these estimates. Predictably, the uncertainty in estimating ROR's rises dramatically for younger and younger cohorts. Secondly, the impact of reforms on cohorts differs substantially depending on the form these policies take. An NRA shift, particularly when delayed, tends to impact cohorts born after 1960 most dramatically. In comparison, an immediate tax increase would spread the cost of reform across generations more equitably. Additionally, the uncertainty resulting from a shift in the NRA would increase substantially for younger cohorts, while an increase in taxes would have a negligible effect on uncertainty.

Finally, it should be noted that our estimates are preliminary in nature. For computational ease we used only two hundred trajectories in these estimates. However we plan on completing more precise calculations incorporating a larger number of trajectories as well as a precise calibration of our simulation according to deterministic forecasts similar to those made by the SSA. 


\section{References}

Anderson, Michael; Tuljapurkar, Shripad; and Lee, Ronald. 1999. "Chances Are: Stochastic Forecasts of the Social Security Trust Fund and Attempts to Save It." Paper presented at the 1999 Conference on Retirement Research, Center for Retirement Research, Boston College. Also presented at 1998 Population Association of America meetings in New York. Working paper, Mountain View Research, Inc. 1999.

Boskin, Michael, J., Laurence J Kotlikoff, Douglas J. Puffert, and John, B. Shoven. 1987. "Social Security: A Financial Appraisal across and within Generations." National Tax Journal, Vol. X, No. 1: 19-34.

Boskin, Michael, and Douglas J. Puffert. 1988. "The Financial Impact of Social Security by Cohort." in Rita Ricardo-Campbell and Edward P. Lazear (Eds.) Issues in Contemporary Retirement, pp. 207-42. Hoover Institution Press: Stanford, CA.

Bosworth, Barry, Gary Burtless, and Eugene Steuerle. 1999. "Lifetime earnings Patterns, the Distribution of Future Social Security Benefits, and the Impact of Pension Reform." Center for Retirement Research at Boston College, Working Paper: 1999-06.

Burkhauser, Richard V. and Jennifer L. Warlick. 1981. "Disentangling the Annuity from the Redistributive Aspects of Social Security in the United States." Review of Income and Wealth, Vol. 27 (December), pp. 401-21.

Freiden, Alan, Dean Leimer, and Ronal Hoffman. 1976. "Internal Rates of Return to Retired Worker-Only Beneficiaries under Social Security, 1967-70." Studies in Income Distribution, No. 5. Office of Research and Statistics, Social Security Administration, US Department of Health, Education, and Welfare.

Geanakoplos, John, Olivia S. Mitchell, and Stephen P. Zeldes. 1998. "Social Security Money's Worth." in Olivia S. Mitchell, Robert J. Myers, and Howard Young (Eds.), Prospects for Social Security Reform, pp. 79-151. University of Pennsylvania Press: Philadelphia, PA. (also NBER Working Paper No. 6722.)

Hurd, Michael D. and John B. Shoven. 1985. "The Distributional Impact of Social Security." In David A. Wise (Ed.), Pensions, Labor, and Individual Choice, pp. 193-221. University of Chicago Press: Chicago, IL.

Lee, Ronald and Lawrence Carter. 1992. "Modeling and Forecasting U.S. Mortality." Journal of the American Statistical Association v.87 n.419 (September, 1992), pp.659-671, and "Rejoinder", same issue, pp.674-675.

Lee, Ronald and Shripad Tuljapurkar. 1994. "Stochastic Population Projections for the U.S.: Beyond High, Medium and Low." Journal of the American Statistical Association, v.89 n.428 (December) pp.1175-1189. 
Leimer, Dean, Ronald Hoffman, and Alan Freiden. 1978. A Framework for Analyzing the Equity of the Social Security Benefit Structure, Studies in Income Distribution, U.S.

Department of Health, Education, and Welfare, Social Security Administration, Office of Research and Statistics.

Leimer, Dean R. 1994. "Cohort-Specific Measures of Lifetime Net Social Security Transfers.” ORS Working Paper No. 59, Office of Research and Statistics, Social Security Administration, February 1994.

, Dean R. 1995. “A Guide to Social Security Money's Worth Issues.” Social Security Bulletin, Vol. 58, No. 2, 3-20.

Myers, Robert J., and Bruce D. Schobel. 1994. "An updated money's-worth analysis of Social Security retirement benefits." Transactions. Society of Actuaries.

Steuerle, C. Eugene and Jon M. Bakija. 1994. Retooling Social Security for the $21^{\text {st }}$ Century: Right and Wrong Approaches to Reform. (Chapter 5. "How Social Security Redistributes Income"), Urban Institute Press: Washington, D. C.

Wolff, Edward N. 1987. "The Effects of Pensions and Social Security on the Distribution of Wealth in the U. S." In E. Wolff (Ed.), International Comparisons of Household Wealth Distribution. Oxford University Research in Economic Inequality, 4:131-57.

1988. "Social Security, Pensions, and the Life Cycle Accumulation of Wealth: Some Empirical Tests." Annales d'Economie et de Statistique, 9(January/March):199-226.

.1992. "Methodological Issues in the Estimation of Retirement Wealth." In D. Slottje (Ed.), Research in Economic Inequality, 2:51-63. 
Figure 1. Real, internal rate of return by cohort, legislated scenario

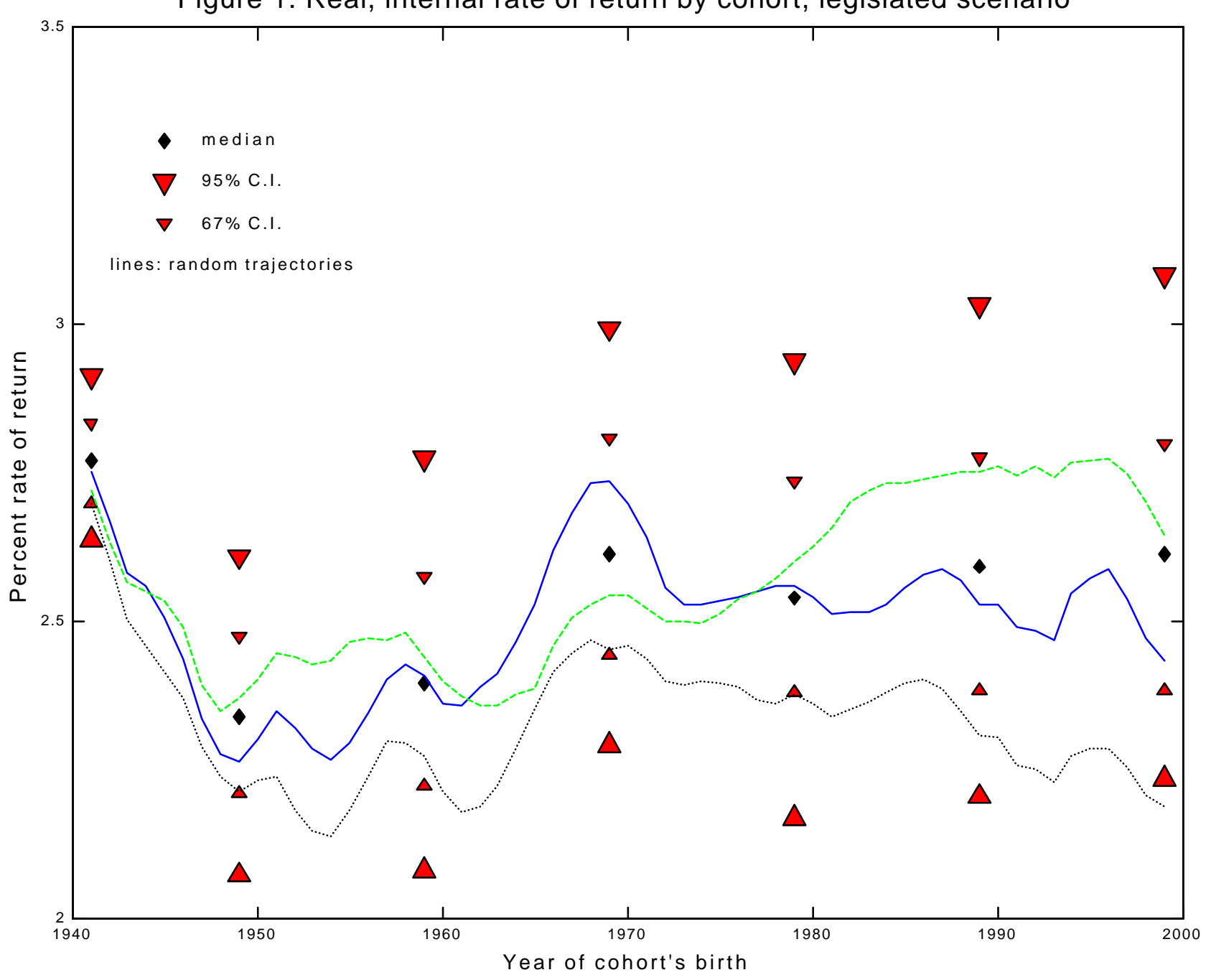


Figure 2. Distribution of rates of return for three cohorts, legislated scenario
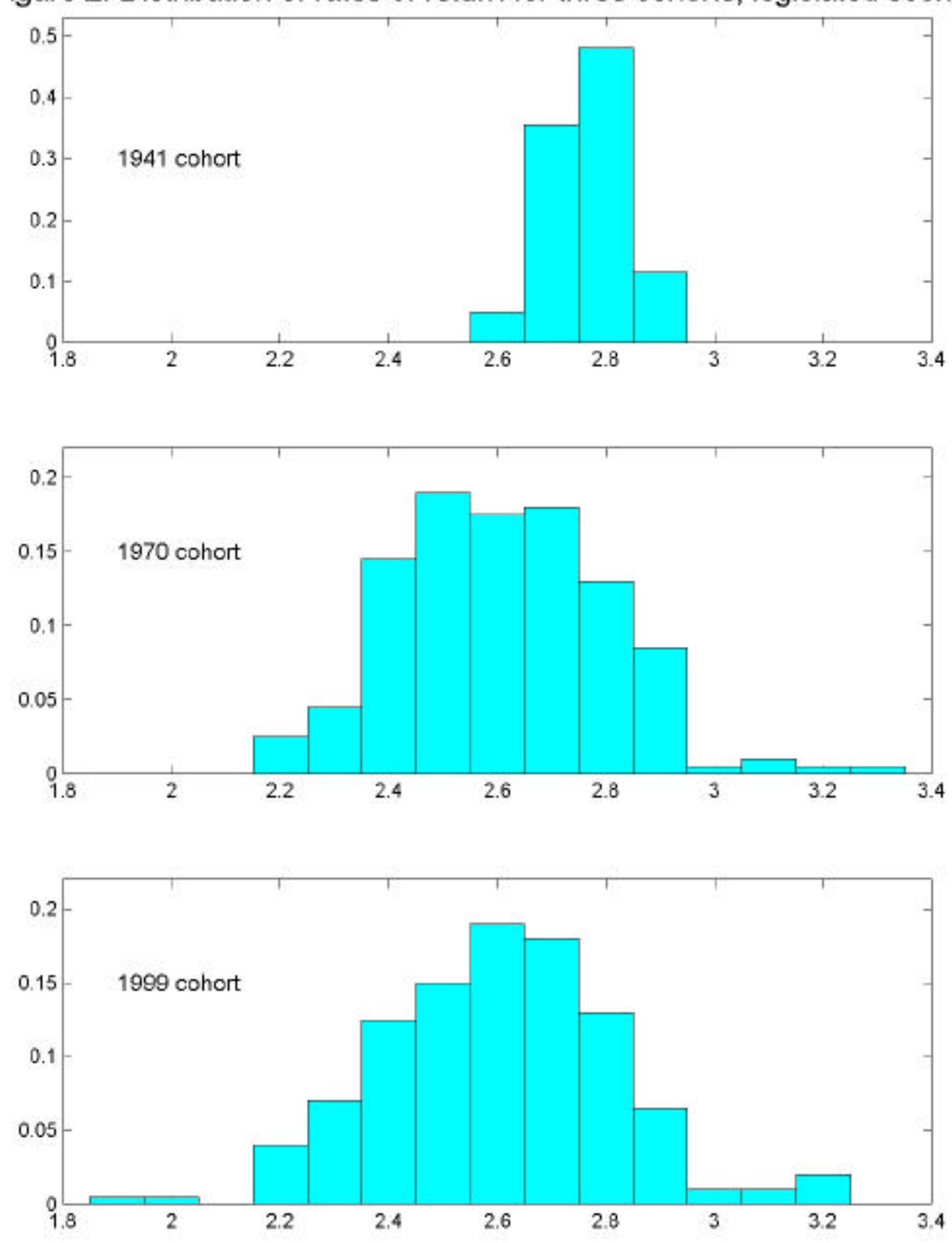
Figure 3. Real, internal rate of return by cohort, $+2 \%$ tax increase

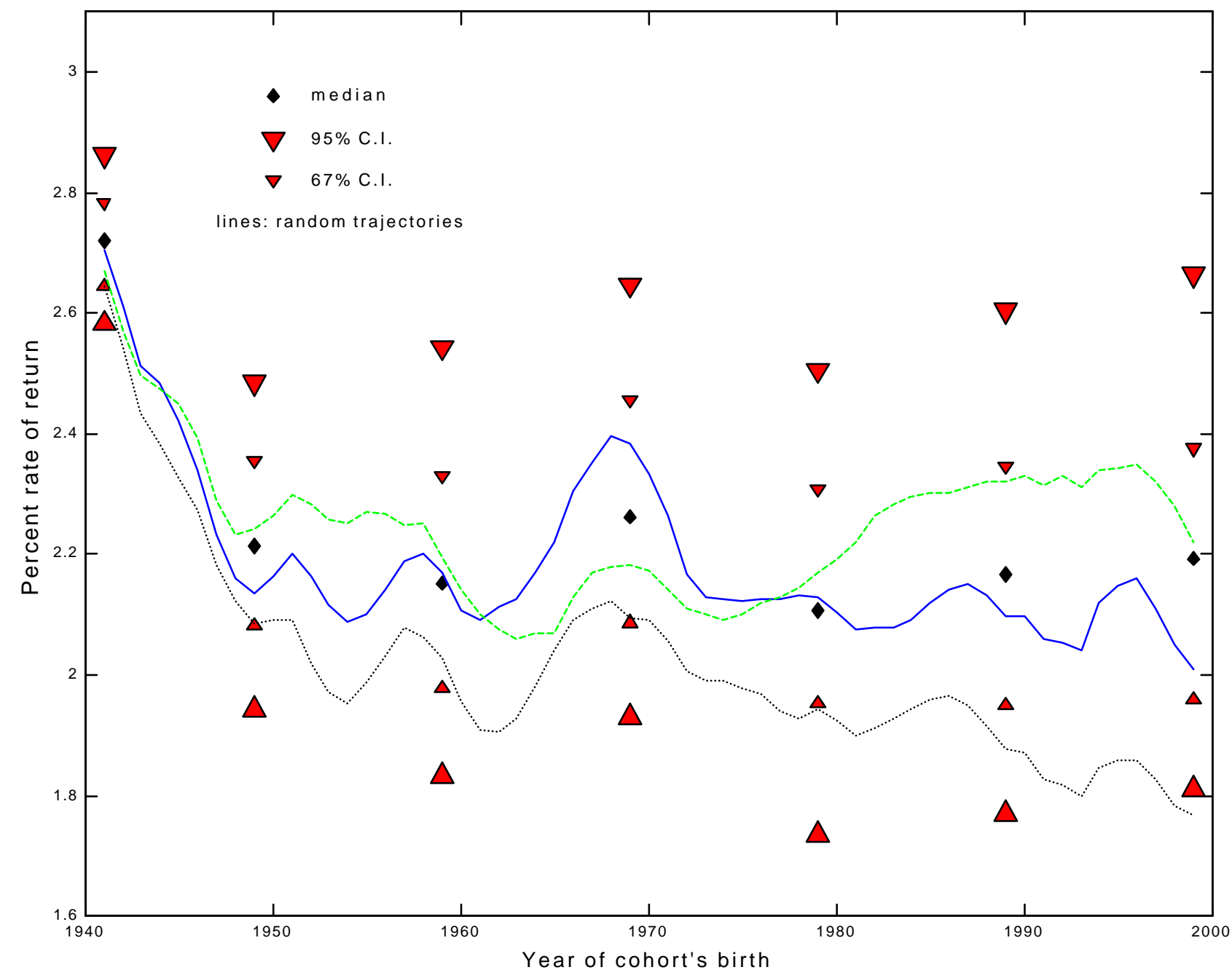


Figure 4. Distribution of rates of return for three cohorts, $2 \%$ tax increase scenaric
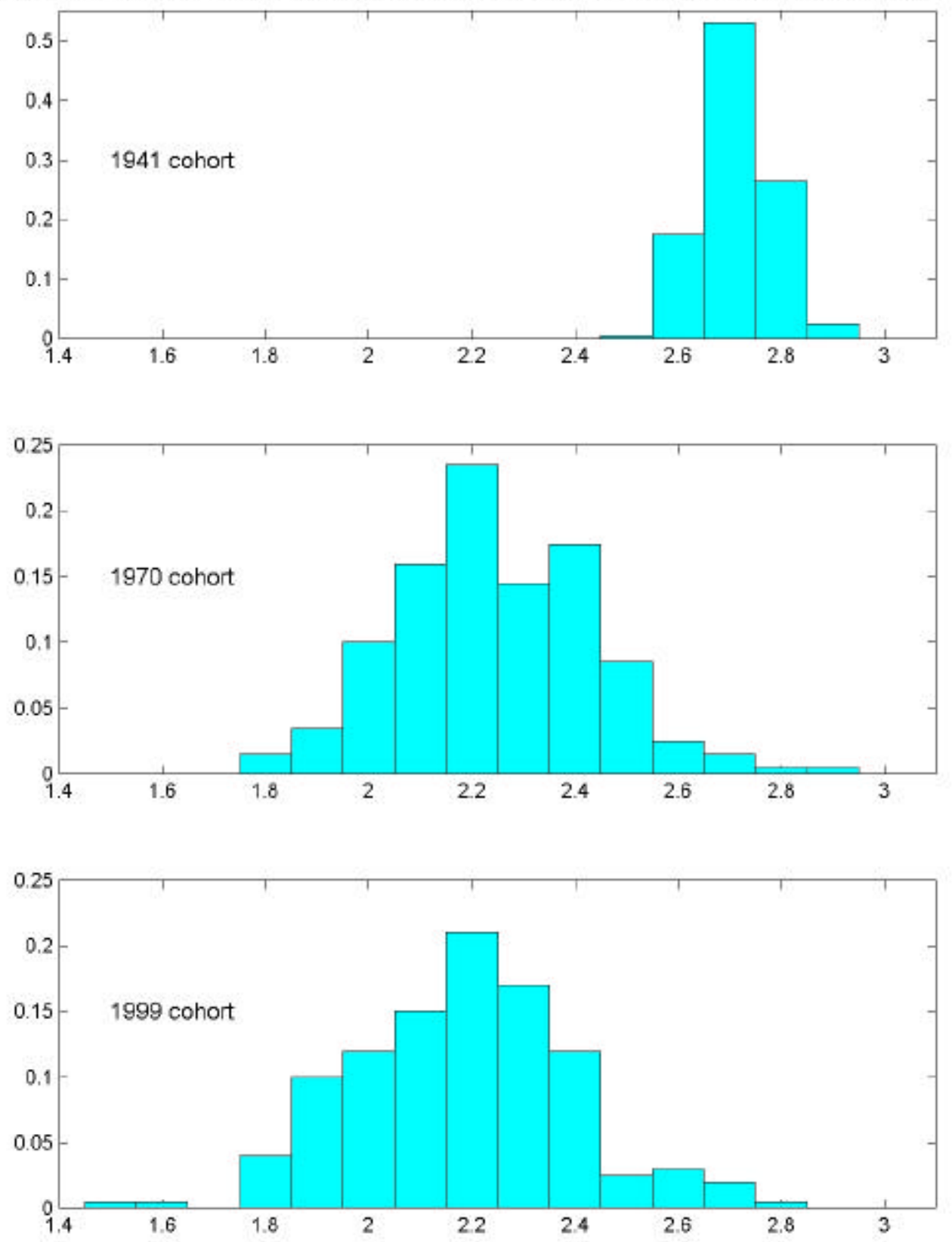
Figure 5. Real, internal rate of return by cohort, NRA increased to 69

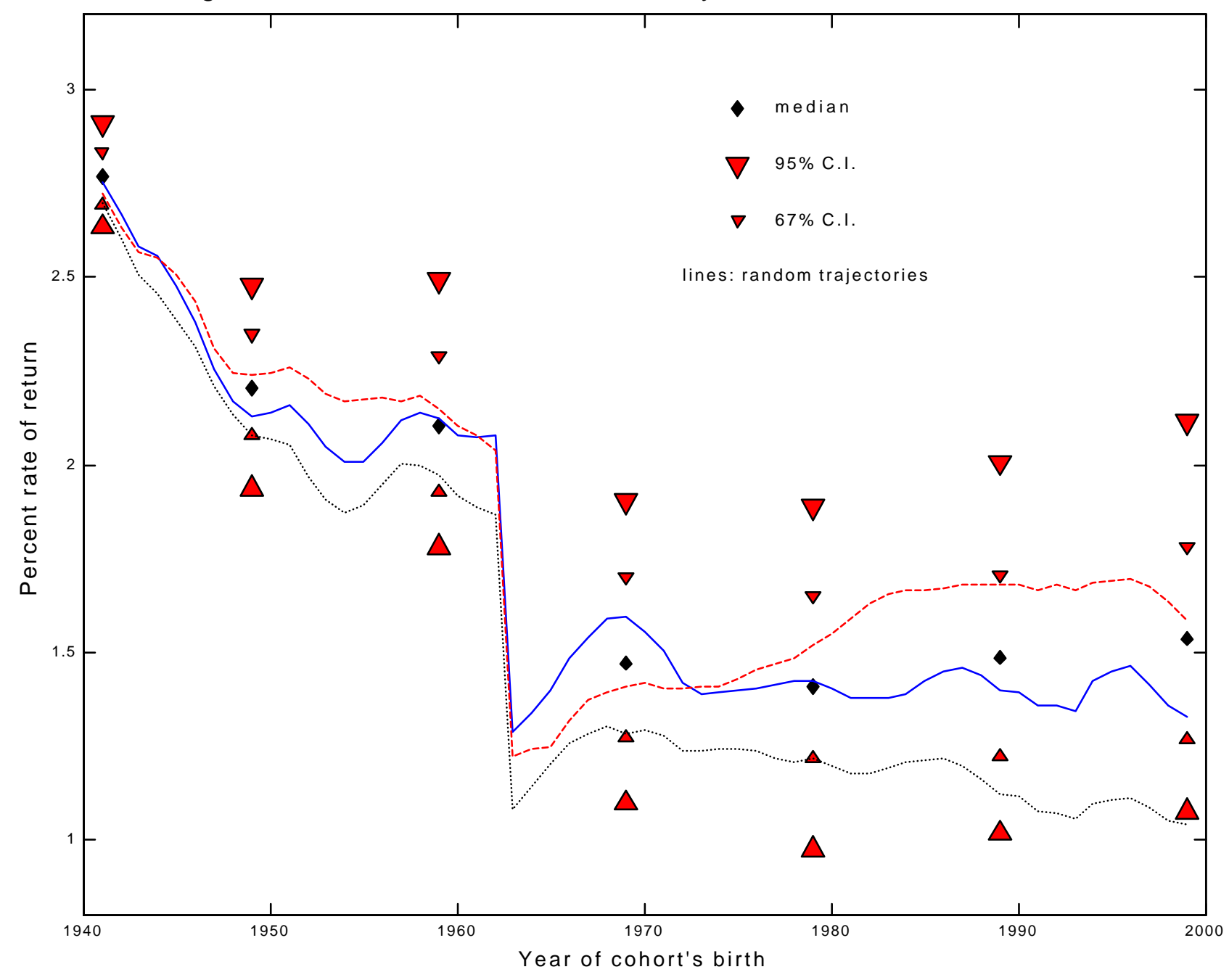


Figure 6. Distribution of rates of return for three cohorts, NRA-to-69 scenario
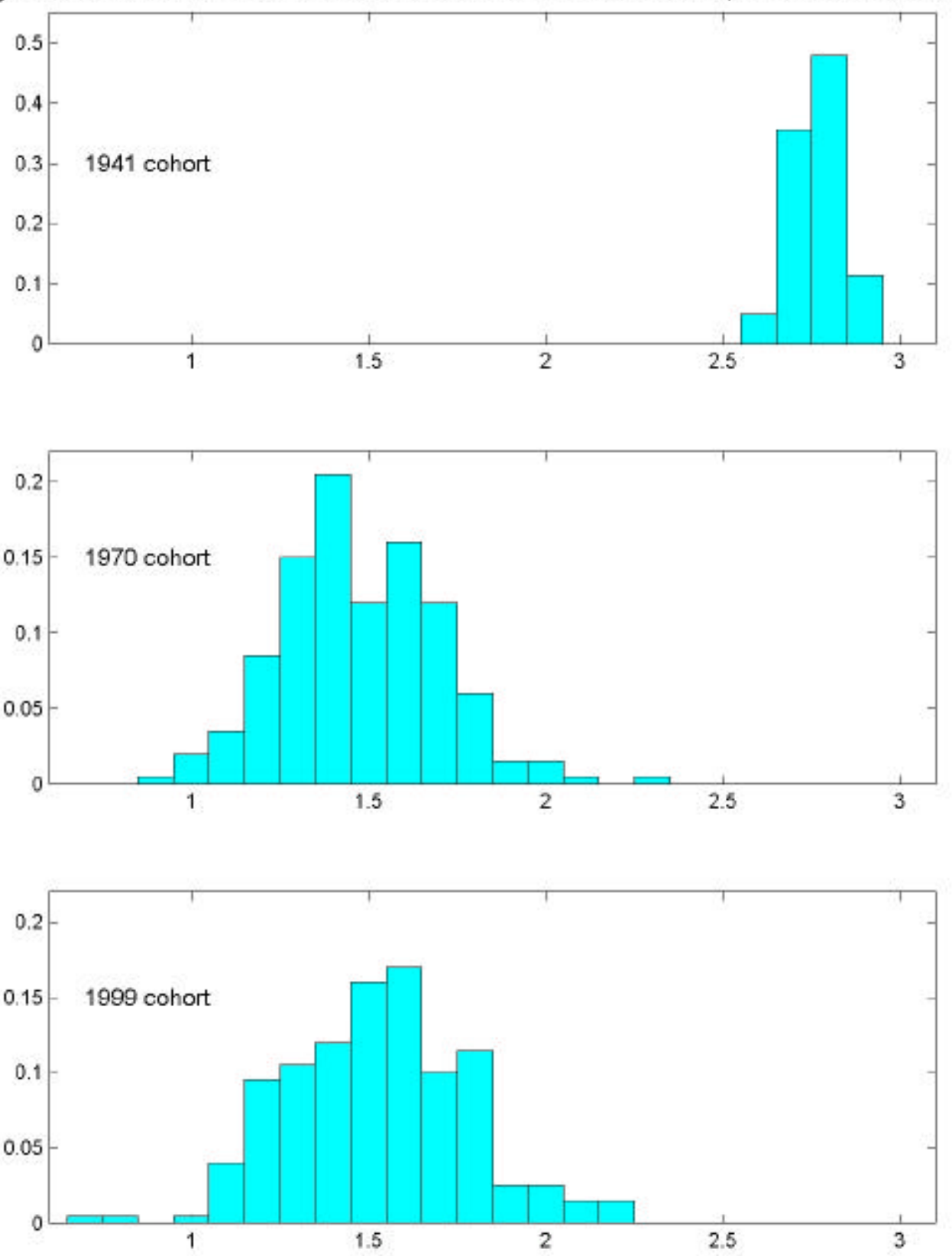
Figure 7. Variance in rate of return estimates by cohort, three scenarios

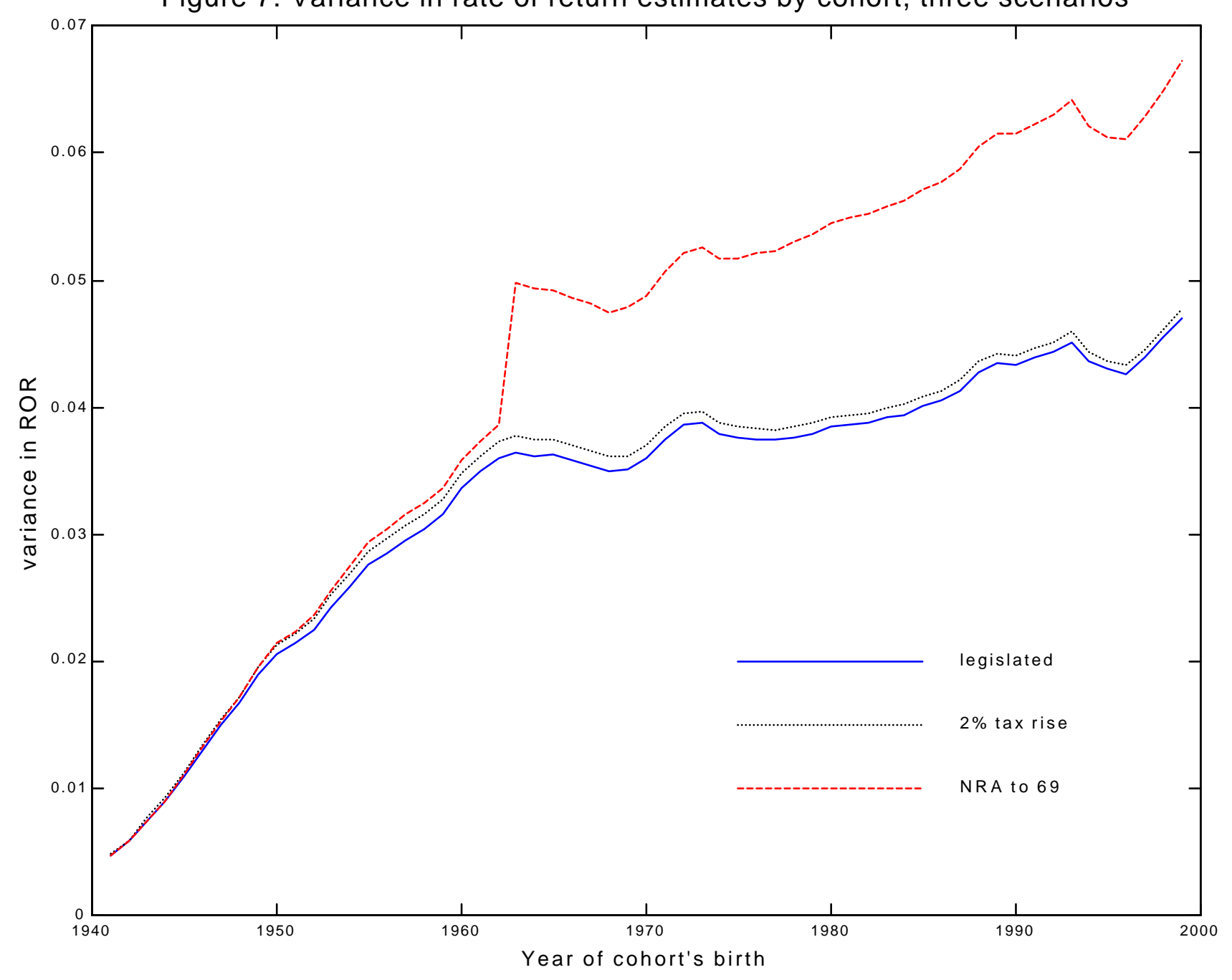

